\title{
Commentary on the effects of hypoxia on energy substrate use during exercise
}

\author{
Andrew J. Young ${ }^{1,2^{*}}$ (D), Lee M. Margolis ${ }^{1}$ and Stefan M. Pasiakos ${ }^{1}$
}

\begin{abstract}
A recently published meta-analysis in this journal analyzed findings from studies comparing substrate use during exercise at the same relative intensity (i.e., \% $\dot{\mathrm{V}} \mathrm{O}_{2} \max$ ) in normoxic and hypoxic conditions. The primary conclusion was that hypoxia had no consistent effects on the contribution of carbohydrate oxidation to total energy expenditure. However, findings from studies comparing exercise at the same absolute intensity in normoxic as hypoxic conditions were not considered in the meta-analysis. Assessment of substrate oxidation using matched absolute intensity leads to different conclusions regarding hypoxic effects on fuel use during exercise, and that experimental model, (i.e., comparing responses to exercise at matched absolute intensity) has more practical application for developing nutritional recommendations for high-altitude sojourners. This commentary will discuss those differences.
\end{abstract}

Keywords: High altitude, Carbohydrate oxidation, Nutrition, Mountaineering

\section{Background}

Despite considerable research, how hypoxic exposure affects energy substrate use, particularly carbohydrate oxidation, during exercise is not fully understood. In that regard, the recent systematic review and metaanalysis reported by Griffiths et al. [1] contributes importantly toward advancing understanding of the mechanisms by which acute hypoxia ${ }^{1}$ affects substrate use during exercise. The primary conclusions of their analyses of 18 reported studies with a total of 170 participants were that the absolute rate of carbohydrate oxidation was lower at high altitude than at sea level, but that there were no consistent differences in percent contributions of carbohydrate and fat oxidation to total energy expenditure, when exercise responses were compared at the same relative exercise intensity (i.e., \% $\dot{\mathrm{VO}}_{2} \max$ at the altitude of the test). Further, feeding state of subjects and exercise intensity employed in the experiments accounted for a large $(42 \%)$ portion of the heterogeneity in the effects

${ }^{1}$ For this commentary, we only consider the effects of exposure to $\leq 24 \mathrm{~h}$ of hypoxia or high altitude.

\footnotetext{
* Correspondence: Andrew.j.young.ctr@mail.mil

${ }^{1}$ U.S. Army Research Institute of Environmental Medicine, 10 General Greene Ave, Bldg 42, Natick, MA 01760, USA

${ }^{2}$ Oak Ridge Institute for Science and Education, Belcamp, MD 21017, USA
}

of altitude on substrate use. Fed subjects and subjects exercising at higher relative intensities exhibited an increased carbohydrate oxidation in hypoxic as compared to normoxic conditions, whereas fasted subjects and subjects exercising at lower relative intensities exhibited a decrease in carbohydrate oxidation in hypoxia as compared to normoxia. Griffiths et al. [1] and others [2] attribute the lower absolute rate of carbohydrate oxidation during exercise at high altitude to the reduction in absolute intensity (power output) required to match relative intensity to that at sea level, while the similar percentage contribution of carbohydrate and fat oxidation during exercise at sea level and high altitude is attributed to the generally accepted principle that the relative mix of carbohydrate and fat oxidized during exercise is primarily regulated by relative intensity.

While Griffith et al.'s [1] approach of comparing only studies in which the relative exercise intensity was matched at sea level and high altitude provides mechanistic insights regarding regulation of substrate oxidation during exercise, the authors' conclusion that their analyses may "inform nutritional strategies for mountaineers, military personnel and athletes during exposure to altitude, subsequently limiting the detrimental exercise performance experienced in such

(C) The Author(s). 2019 Open Access This article is distributed under the terms of the Creative Commons Attribution 4.0 International License (http://creativecommons.org/licenses/by/4.0/), which permits unrestricted use, distribution, and 
conditions" seems to overstate the practical application of their findings. In order to match relative intensities of exercise, the absolute exercise intensity must be lower at high altitude than sea level to offset the reduction in $\dot{\mathrm{VO}}{ }_{2}$ max associated with hypoxemia at high altitude. However, since any given physical activity requires the same absolute energy (i.e., muscle power output and energy expenditure) in hypoxia as normoxia [3], findings obtained using this experimental model (matching relative exercise intensities in normoxia and hypoxia) lack practical translation to the real world. For that reason, nutritional strategies to optimize performance of mountaineers, soldiers and athletes performing at high altitude are best based on observations from experiments comparing substrate use at the same absolute exercise intensities and exergy expenditure rates in hypoxia as normoxia.

\section{Discussion}

n contrast to comparing substrate oxidation during exercise at the same relative intensity in normoxic and hypoxic conditions, comparing exercise at the same absolute intensity generally indicates a greater contribution of carbohydrate oxidation to total energy expenditure in hypoxic than normoxic conditions (Table 1). For example, Lundby and Van Hall [2] observed that carbohydrate oxidation accounted for $74 \%$ of total energy expenditure in subjects cycling at $45 \% \dot{\mathrm{VO}}_{2} \max (154 \mathrm{~W})$ at sea level compared to $75 \%(p>0.05)$ when cycling at the same relative intensity at $4,100 \mathrm{~m}$ altitude. However, when these same subjects cycled at the same absolute intensity at high altitude as at sea level (154 W), carbohydrate oxidation was higher than at sea level, and accounted for $87 \%(p \leq 0.05)$ of total energy expenditure during exercise at high altitude, compared to the $75 \%$ contribution at sea level. Subsequently, Peronnet et al. [4] confirmed those findings, observing that in subjects cycling at $169 \mathrm{~W}$ at both sea level and $4,300 \mathrm{~m}$ altitude, the contribution of carbohydrate oxidation to total energy expenditure increased from $75 \%$ at sea level to $92 \%$ at altitude $(p \leq 0.05)$. The more pronounced increment in carbohydrate oxidation with hypoxia observed by Peronnet et al. [4] than Lundby and Van Hall [2], appeared due to the larger increase in relative intensity under hypoxic conditions (higher altitude, greater decrease in $\dot{\mathrm{V}} \mathrm{O}_{2} \max$ ), which is consistent with the conclusions Griffiths et al. [1] drew from their meta-analysis.

So how do these observations "inform nutritional strategies for mountaineers, military personnel and athletes during exposure to altitude?" Three reported studies have examined the impact of feeding exogenous carbohydrate on substrate oxidation during steady-state aerobic exercise at high altitude compared to at sea level [4-6]. O'Hara et al. [5] reported that total carbohydrate oxidation rate was lower at high altitude than at sea level, due to reductions in both exogenous and endogenous carbohydrate oxidation and increased fat oxidation. However, O'Hara et al. [5] compared substrate oxidation during exercise matched for relative intensity at sea level and high altitude, so the absolute exercise intensity was lower at high altitude than sea level. As discussed above, since any given physical activity requires the same absolute energy (i.e., muscle power output and energy expenditure) in hypoxia as normoxia, the findings from the experimental model used in that study [5], while informative for understanding regulatory mechanisms, do not seem to have practical application to formulating real-world nutritional guidance.

In contrast, Peronnet et al. [4], compared the effects of feeding exogenous carbohydrate on substrate oxidation during exercise matched for absolute intensity. Using this experimental model, total carbohydrate oxidation rate was higher during exercise at high altitude than sea level, but oxidation of exogenous carbohydrate was not different from sea level (although numerically, it was lower at high altitude). These findings indicate that the increased total carbohydrate oxidation was entirely supported by increased oxidation of endogenous carbohydrate stores. Similarly, our laboratory recently reported [6] that total carbohydrate oxidation rate was the same at $4,300 \mathrm{~m}$ as at sea level during exercise matched for absolute intensity, but oxidation rate of exogenous carbohydrate was lower at high altitude. The differences in the effect of acute hypoxia on total carbohydrate oxidation rate observed by Peronnet et al. [4] and our laboratory [6] are likely attributable to the substantially lower exercise intensity performed by participants in our study compared to that used by Peronnet et al. Collectively, it seems that during performance of a given physical task, whether aerobic exercise or prolonged strenuous work, reliance on carbohydrate oxidation for meeting energy requirements is at least the same and probably greater at high altitude than at sea level. However, feeding exogenous carbohydrate during exercise may not be as effective in sparing endogenous carbohydrate stores during exercise or work at high altitude as has been shown at sea level. Clearly, more research is needed to develop optimal carbohydrate feeding strategies for high-altitude sojourners.

\section{Conclusion and perspectives}

In summary, the meta-analysis by Griffiths et al. [1] of studies comparing substrate metabolism during exercise at the same relative intensity in normoxic and hypoxic conditions contributes greatly to our understanding of the mechanisms by which hypoxia alters substrate metabolism during exercise. However, studies comparing substrate metabolism during exercise at the same 


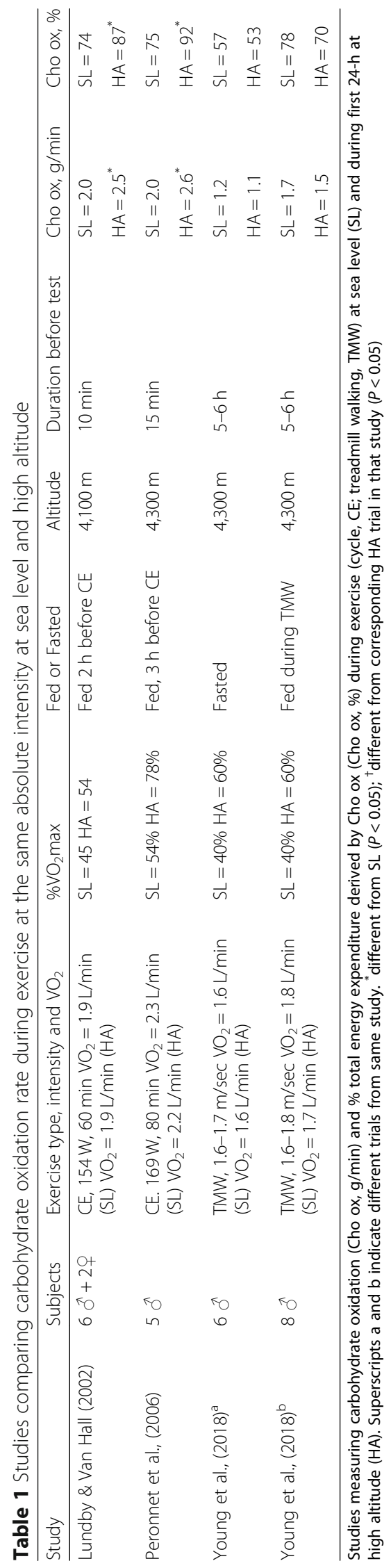


absolute intensity in normoxic and hypoxic conditions provide the practical evidence basis for developing nutritional strategies to optimize physical performance during sojourns at high altitude. Both experimental approaches, matching relative intensity and matching absolute intensity at sea level and high altitude, are useful models. Going forward, scientists investigating effects of high altitude on energy metabolism should consider which approach most appropriately addresses their questions, or whether perhaps combining those approaches would provide an even better design.

\section{Acknowledgements \\ Not applicable.}

\section{Conflict of interest}

The opinions or assertions contained herein are the private views of the authors and are not to be construed as official or as reflecting the views of the Army or the Department of Defense. Any citations of commercial organizations and trade names in this report do not constitute an official Department of the Army endorsement of approval of the products or services of these organizations.

\section{Authors' contributions}

AJY drafted the manuscript, all authors reviewed and edited the manuscript and approved the final version.

\section{Funding}

Funding support for this work was provided by the US Army Medical Research and Materiel Command.

Availability of data and materials

Not applicable.

Ethics approval and consent to participate

Not applicable.

\section{Consent for publication}

Not applicable.

\section{Competing interests}

The authors declare that they have no competing interests.

Received: 14 May 2019 Accepted: 3 July 2019

Published online: 12 July 2019

\section{References}

1. Griffiths A, Shannon OM, Matu J, King R, Deighton K, O'Hara JP. The effects of environmental hypoxia on substrate utilisation during exercise: a metaanalysis. J Int Soc Sport Nutr. 2019;16.

2. Lundby C, Van Hall G. Substrate utilization in sea level residents during exercise in acute hypoxia and after 4 weeks of acclimatization to $4100 \mathrm{~m}$. Acta Physiol Scand. 2002;176(3):195-201.

3. Saltin B, Grover RF, Blomqvist CG, Hartley LH, Johnson RL. Maximal oxygen uptake and cardiac output after 2 weeks at $4300 \mathrm{~m}$. J Appl Physiol. 1968;25:400-9.

4. Peronnet F, Massicotte D, Folch N, Melin B, Koulmann N, Jimenez C, et al. Substrate utilization during prolonged exercise with ingestion of (13) Cglucose in acute hypobaric hypoxia (4,300 m). Eur J Appl Physiol. 2006;97(5): $527-34$

5. O'Hara JP, Woods DR, Mellor A, Boos C, Gallagher L, Tsakirides C, et al. A comparison of substrate oxidation during prolonged exercise in men at terrestrial altitude and normobaric normoxia following the coingestion of 13C glucose and 13C fructose. Physiol Rep. 2017;5(1).

6. Young AJ, Berryman CE, Kenefick RW, Derosier AN, Margolis LM, Wilson MA et al. Altitude acclimatization alleviates the hypoxia-induced suppression of exogenous glucose oxidation during steady-state aerobic exercise. Front Physiol. 2018;9:830.

\section{Publisher's Note}

Springer Nature remains neutral with regard to jurisdictional claims in published maps and institutional affiliations.
Ready to submit your research? Choose BMC and benefit from:

- fast, convenient online submission

- thorough peer review by experienced researchers in your field

- rapid publication on acceptance

- support for research data, including large and complex data types

- gold Open Access which fosters wider collaboration and increased citations

- maximum visibility for your research: over $100 \mathrm{M}$ website views per year

At BMC, research is always in progress.

Learn more biomedcentral.com/submissions 